\title{
Impacts of Mau Forest Catchment on the Great Rift Valley Lakes in Kenya
}

\author{
Mark Kipkurwa Boitt \\ Department of Geomatic Engineering and GIS, Jomo Kenyatta University of Agriculture and Technology, \\ Nairobi, Kenya \\ Email: mboitt@jkuat.ac.ke
}

Received 8 April 2016; accepted 17 May 2016; published 20 May 2016

Copyright (C) 2016 by author and Scientific Research Publishing Inc.

This work is licensed under the Creative Commons Attribution International License (CC BY). http://creativecommons.org/licenses/by/4.0/

c) (i) Open Access

\section{Abstract}

Remote sensing and GIS applications are being widely used for various projects relating to natural resource management. Forests are very important national assets for economic, environmental protection, social and cultural values and should be conserved in order to realize all these benefits. Kenya's forests are rapidly declining due to pressure from increased population, technological innovation, urbanization human development and other land uses. Mau forest is one of the major forests in Kenya that is a catchment area for many Great Rift Valley lakes within the country and faces a lot of destruction. Continued destruction of the Mau forest will cause catastrophic environmental damage, resulting in massive food crises and compromising the livelihoods of millions of Kenyans, and the possible collapse of the tourism industry. The purpose of this research was to investigate the relationship between the increasing rate of deforestation and the reduction of the volumes of water in the neighboring lakes between the years 1989 to 2010 . Satellite images from Landsat-5 Thematic Mapper (TM) and Landsat-7 Enhanced Thematic Mapper (ETM+) were used for the detection of changes in the Mau forest and the dynamics of the neighboring water bodies that included lakes: Naivasha, Baringo, Nakuru, Elementaita and Bogoria. The research showed that from a period of 1989 to 2010 Mau forest has been decreasing due to deforestation and the water bodies have irregular dynamics in that, from 1989 to 2000, there was rise in the volume of water, this is attributed to the El Nino rains experienced in the country during the year 1997 and 1998. But between 2000 and 2010 the volume decreased as the forest is also decreasing. It is recommended that the government creates awareness to sensitize the public on the importance of such forests as catchment areas in Kenya.

\section{Keywords}

Environmental Protection, Natural Resource Management, Land Use, Forest Cover, Water Reduction, Normalized Difference Vegetation Index, Classification 


\section{Introduction}

\subsection{Remote Sensing for Forest Mapping}

Remote sensing is defined as the technique of obtaining information about objects through the analysis of data collected by special instruments that are not in physical contact with the objects of investigation. As such, remote sensing can be regarded as "reconnaissance from a distance", "tele detection", or a form of the common adage "look but don't touch". Remote sensing thus differs from in situ sensing, where the instruments are immersed in, or physically touch, the objects of measurement. A common example of an in situ instrument is the soil thermometer. Many techniques have been used to quantify forests. For instance, airborne remote sensing has been widely been used in Kenya [1]-[3].

\subsection{Forests in Kenya}

Forest ecosystems provide a continuous flow of essential goods and services that support, directly and indirectly, the Kenyan economy, whose main pillars are agriculture and unique natural ecosystems [4]. Closed forests are crucial water catchments, and harbor a disproportionate amount of Kenya's biodiversity. Among these forests, the five largest blocks are Mt. Kenya, the Aberdare Range, the Mau Complex, Mt. Elgon and the Cherangani Hills. These montane forests constitute the main "water towers" of Kenya and form the upper catchment of all main rivers in Kenya. These catchments provide water to all installed hydro-power plants that produce some 70 percent of Kenya's total electricity output. These montane forests are surrounded by the most densely populated areas of Kenya, because they cause increased precipitation in the rainy seasons and ensure permanent river flow in the dry seasons [5].

Notwithstanding the services they provide to the people of Kenya, these forests have been and remain the target of uncontrolled and unplanned development activities. Over the last decades, Kenya's civil society has become much more vocal about forest destruction and has shown an increased ability to challenge bad environmental governance. But updated information on the status of and on-going activities in most of these forests is often unavailable. This limits the civil society and other concerned stakeholders' advocacy and lobbying efforts against unwise developments that could jeopardize the integrity of these ecosystems and the continuous flow of services they provide.

Forests are important in conservation of biological diversity, water, soil and are major habitat for wildlife [6] The importance of forest in the country's development cannot be underestimated, because all sectors of the economy, that is water, agriculture, tourism, power and other industries depend on the substantial healthy forest ecosystem. Despite their immense importance, the country has witnessed substantial loss of forest cover in the recent past both within the gazetted forest, trust lands as well as in the private land. Considering all these benefits which can be reaped from the forest, it is important to protect and nurture our remaining forest and invest in now and future forest [7]. The general size of forest has been reducing over the years. There are several reasons that explain the causes of destruction and they include: human population increase which has exerted demand for agricultural land, logging (both legal and illegal), poor understanding of the benefit accrued from forest especially by communities, which live around the forest hence leading to poor management of forest, lack of sound programmes on forest management, forest fires also consume large chunks of forest cover especially in times of droughts among other causes.

\subsection{Mau Forest}

Mau Forest is a forest complex in the Rift Valley of Kenya. It is the largest indigenous montane forest in East Africa. The Mau Forest complex has an area of 273,300 hectares (675,000 acres). The forest area has some of the highest rainfall rates in Kenya. Mau Forest is the largest water catchment area in Kenya [8]. Numerous rivers originate from the forest, including EwasoNy'iro river (southern), Sondu river, Mara river and Njoro river hence the main catchment of critical lakes and wetlands in the Rift Valley, including lakes Baringo, Nakuru, Naivasha, Natron and Turkana. Mau Complex is also very rich in flora and fauna. Mau complex forest has been used to depict the problem of depletion which has adverse effect on the volume of neighbouring water bodies, Experts have already warned that the continued destruction of the Mau forest will cause catastrophic environmental damage, resulting in massive food crisis and compromising the livelihoods of millions of Kenyans, and the possible collapse of the tourism industry [9]-[11]. 


\subsection{Land Cover and Land Use}

Land cover is the physical material at the surface of the earth. Land covers include grass, asphalt, trees, bare ground, water, etc. There are two primary methods for capturing information on land cover: field survey and analysis of remotely sensed imagery, [12]. Land cover is distinct from land use despite the two terms often being used interchangeably. Land use is a description of how people utilize the land and socio-economic activity. Urban and agricultural land uses are two of the most commonly known land use classes. At any one point or place, there may be multiple and alternate land uses, the specification of which may have a political dimension. The origins of the "land cover/land use" couplet and the implications of their confusion [13].

\subsection{Study Area}

The area of study is the Mau complex forest and its main neighboring lakes and wetlands in the Rift Valley, including Lake Baringo, Lake Nakuru, Lake Naivasha, Lake Elementaita, and Lake Bogoria (Figure 1).

\subsection{Rainfall Variation in Central Kenya}

Mau Complex is closely located in the central part of Kenya though a little bit to the western part. The variation in rainfall has been seen to have various dynamic changes in this region. El Nino rains was experienced in central Kenya in 1997 and it caused a lot of effects to agriculture (Figure 2). The authors (Figure 2) used historical data from 70 rainfall stations and 17 air temperature stations to interpolate the long-rains precipitation and temperature trends for all of Kenya from 1960 to 2009. In Kenya, long-rains traditionally occur between March and June. They reported that in Central Kenya, one of the countries key agricultural regions, the area receiving adequate rainfall to support reliable rain-fed agriculture has declined by roughly 45 per cent since the mid-1970s.

\section{Materials and Methods}

The study was done using satellite images to show the change in forest cover and the dynamics of neighbouring

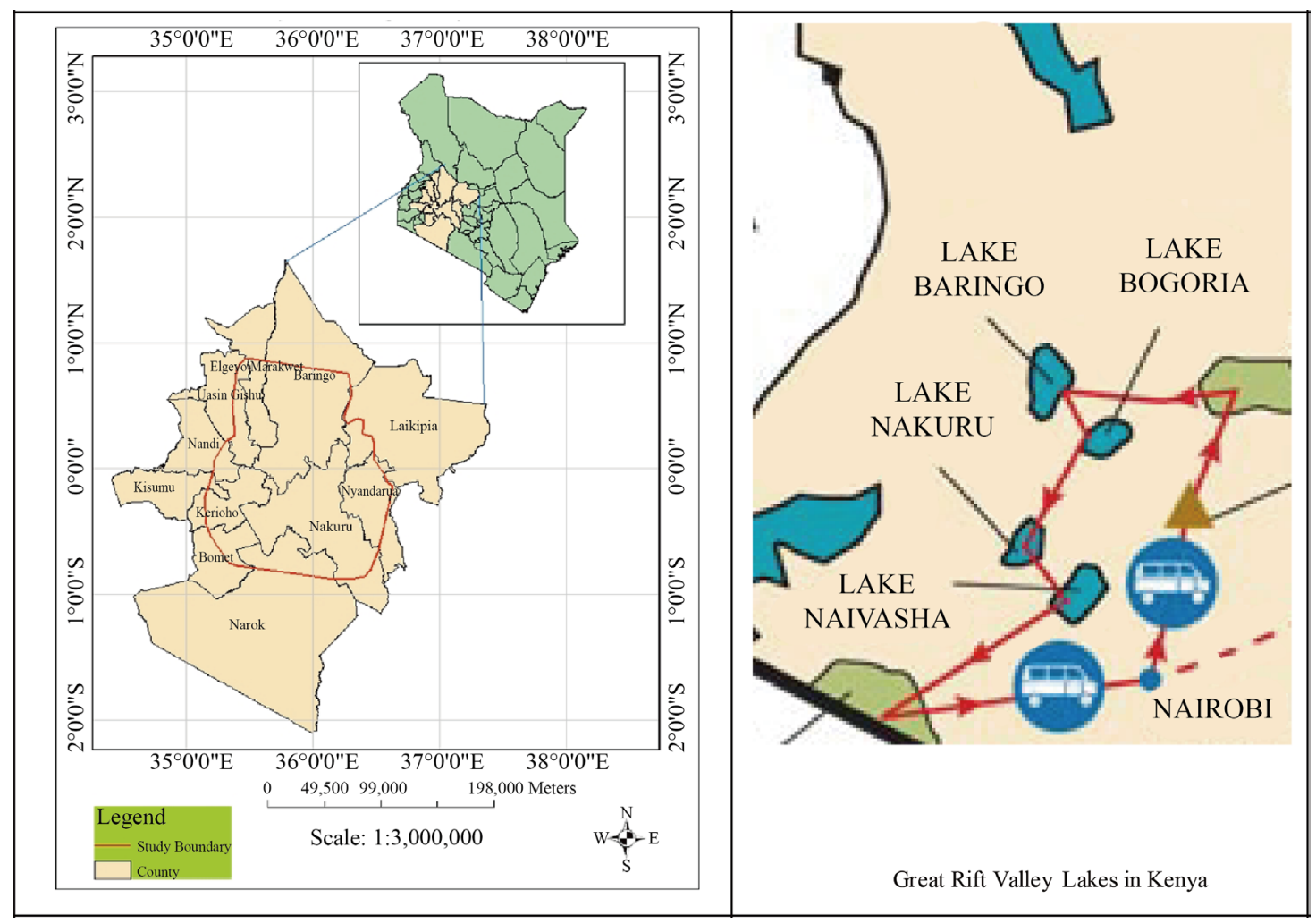

Figure 1. Mau Forest showing the lakes surrounding the catchment area. 


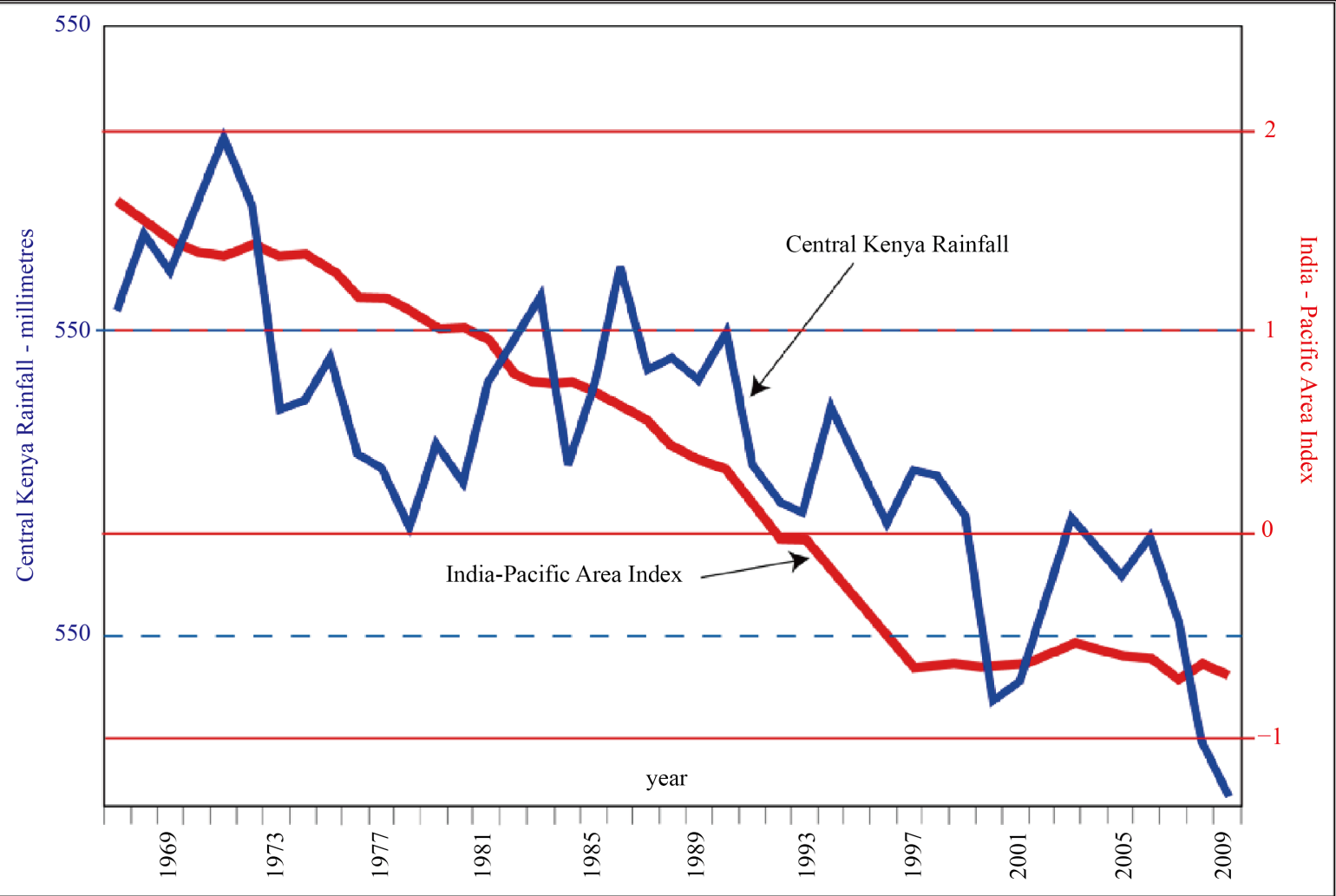

Figure 2. The trend in rainfall for Kenya since the 1960s tracks the trend in the Indian-Pacific Area circulation index-a measure of temperature and precipitation over the Indian and Western Pacific Ocean. Yellow line shows the time of this research study (Source: UNEP-NET).

lakes over a period of time that is from 1989 to 2010. The process adopted include: Data collection, data evaluation, data processing, data analysis and data presentation. Three Landsat images were used in this analysis of land use/cover change. The characteristics of the satellite data used in this project are summarized in the Table 1.

\subsection{Image Processing and Classification}

For the images to be accurately interpreted there were several analyses undertaken. The following are some of the processing undertaken; they include: Layer stacking, georeferencing, geometric corrections, resampling and interpolation of the images. Classification is the process of sorting pixel into a finite number of individual classes, or categories of data, based on their data file values. The assessment of land use and land cover was done by adopting a classification scheme for the Lands at images for years 1989, 2000 and 2010 and carrying out a Supervised classification (Maximum likelihood) based on auxiliary data from thematic maps and information from local knowledge of the area. By identifying patterns, the computer system was instructed to identify pixels with similar characteristics. Since the main objective was to show change in the forest cover and water bodies dynamics, it was important to differentiate pixel according to dense forest, scattered forest and grassland or deforested areas.

\subsection{Normalized Difference Vegetation Index}

Normalized Difference Vegetation Index (NDVI) is a ratio often used to determine the density of vegetation in an area based on visible and near infra-red (NIR) sunlight reflected by plants. The more leaves a plant has, the more these wavelengths of light are affected. The normalized difference is preferred to the simple index as it compensates for illumination conditions such as surface slope and orientation. Vegetated areas will give positive values due to their high reflectance in NIR and low reflectance in the visible spectrum [14]. On the other hand, 
Table 1. Data sets.

\begin{tabular}{cccc}
\hline Satellite & Sensor & Acquisition Date & Spatial resolution (Meters) \\
\hline Landsat TM & Landsat 5 & $2 / 11 / 1989$ & 30 \\
Landsat ETM+ & Landsat 7 & $10 / 17 / 2000$ & 28.5 \\
Landsat ETM+ & Landsat 7 & $24 / 7 / 2010$ & 28.5 \\
\hline
\end{tabular}

bare area or areas with very sparse vegetation cover have higher reflectance in the visible spectrum than in NIR, leading to negative and near zero NDVI values. Mathematically NDVI can be expressed as:

$$
\mathrm{NDVI}=\frac{(\mathrm{NIR}-\mathrm{R})}{(\mathrm{NIR}+\mathrm{R})}
$$

where:

NIR is near infra-red band.

$\mathrm{R}$ is red band.

This technique was used to determine the density of forest before running the main classification.

\section{Results and Discussion}

\subsection{Image Classification and Accuracy Assessment}

The images were classified for analysis. Figures below show the colour composites and the corresponding classified imagery for 1989, 2000 and 2010 respectively. Accuracy assessments were performed using a high resolution image (rapid eye) and the overall accuracies for the 1989, 2000 and 2010 were $76 \%, 81 \%$ and $83 \%$ respectively. Analysis was undertaken after classification. Figures 3-5 shows the results obtained.

\subsection{Results}

All the classified images were analysed based on the areas covered by different land uses. These land uses include: Forested area, water, built up, farmlands, and plantations. Further, each land use was quantified as a percentage of the total area it occupies on the entire study area. Figure 6 and Figure 7 shows these.

Figure 6 shows a graphical representation of the result. The dynamics of the Great Rift Valley lakes in Kenya due to water reduction and expansion is as shown on Figure 7.

\subsection{Discussions}

Image classification of the Lands at satellite images for 1989, 2000 and 2010 was successfully performed and results shown in Figures 3-5. Comparing the classified images from the year 1989 to 2010 there is evidence forest cover change as a result of deforestation. Furthermore, normalized difference vegetation index was performed as well to depict the forest cover changes for the years. From the statistics most of the land use/cover experienced changes in terms of area occupied. Forested areas reduced from $15 \%$ in the year 1989 to $13 \%$ in 2010 (Figure 6). The area coverage of water bodies had some dynamics in that there is increase from $1.4 \%$ to 1.5\% in the year 1989 and 2000 respectively and then a decrease to 1.3\% in the year 2010 (Figure 7). This increase is attributed to the increased rains of 1997 and part of 1998 Elnino rains in Kenya (Figure 2). Similar and related studies that was for monitoring land use changes in Nakuru municipality [15] showed that water bodies from 1990 to 2000 increased in Lake Nakuru. UNEP also shows statistical tabulation of the variations of rainfall in central Kenya from 1969 to 2009 (Figure 2) and it shows that there was extreme rainfall in the year 1997 which was El Nino rains.

Forest cover destruction (human activities) from research shows that, built up areas increased from $8.8 \%$ in the year 1989 to $17.3 \%$ in the year 2010. Farmlands reducing from $72.7 \%$ in the year 1989 to $66.9 \%$ in 2010 and plantation had the dynamics of increasing from $1.9 \%$ in the year 1989 to $30.6 \%$ in 2000 and decreasing to $1.5 \%$ in the year 2010.From the statistics between the years 1989 to 2000 all the lakes had a volume increase of water apart from Lake Elementaita which had a decrease of 0.18\%. Lake Bogoria registered the highest increase of 28.22\% whereas Lake Baringo had the lowest increase of 2.93\%. Similarly, Lake Nakuru had $11.77 \%$ and Lake 

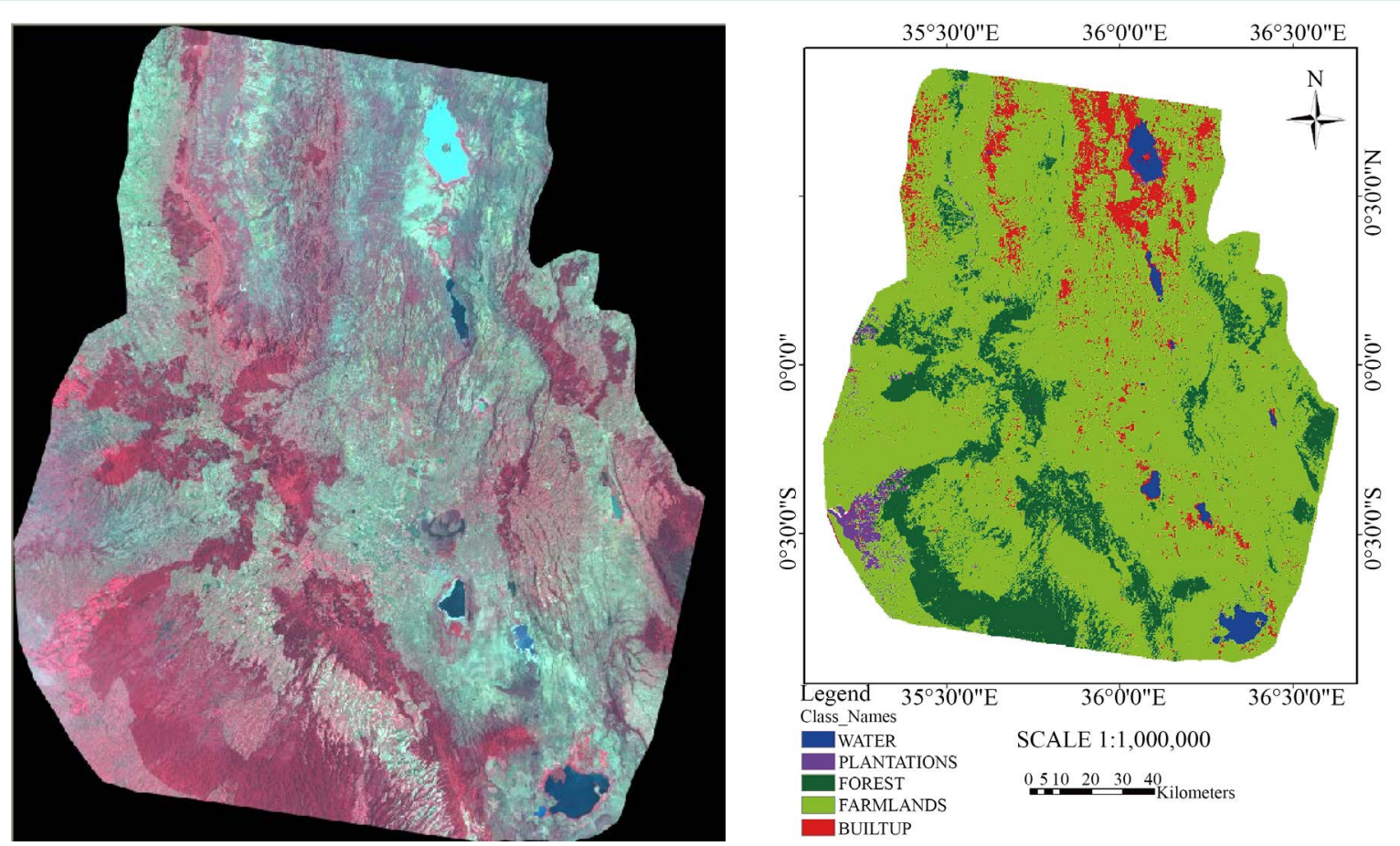

Figure 3. Landsat TM 1989 image and its classification.
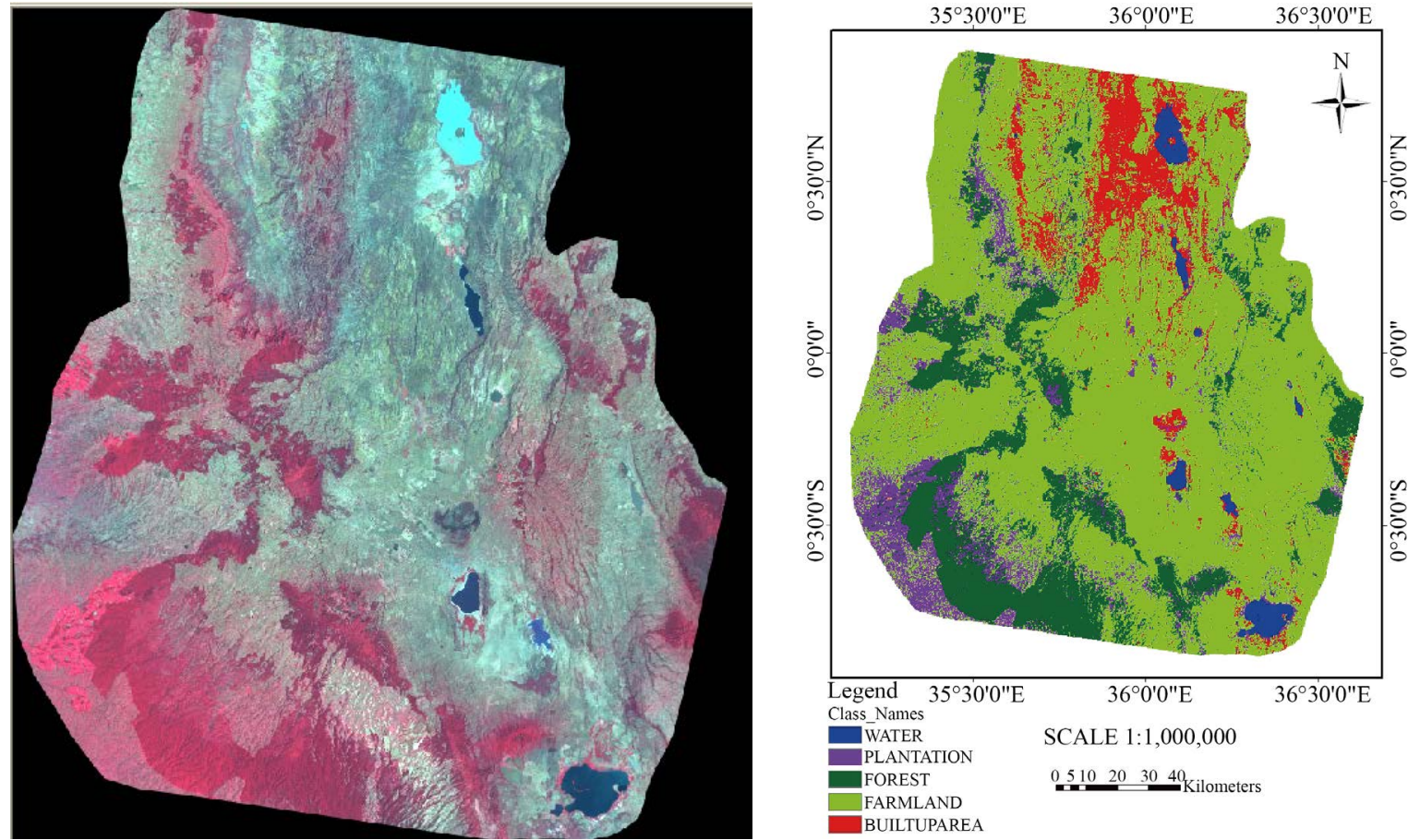

Figure 4. Landsat ETM+2000 image and its classification.

Naivasha equivalent to $13.08 \%$. The possible factor which might have led to this increase is the El Nino rains experienced in the country in the year 1997 and 1998 (Figure 2). The rains were more than the expected in Kenya and it caused the rivers to increase in their flow hence increasing surface area on the lakes they flow to. Between the year 2000 and 2010, all the lakes had decrease in water volumes which was also the same as the forest cover. 

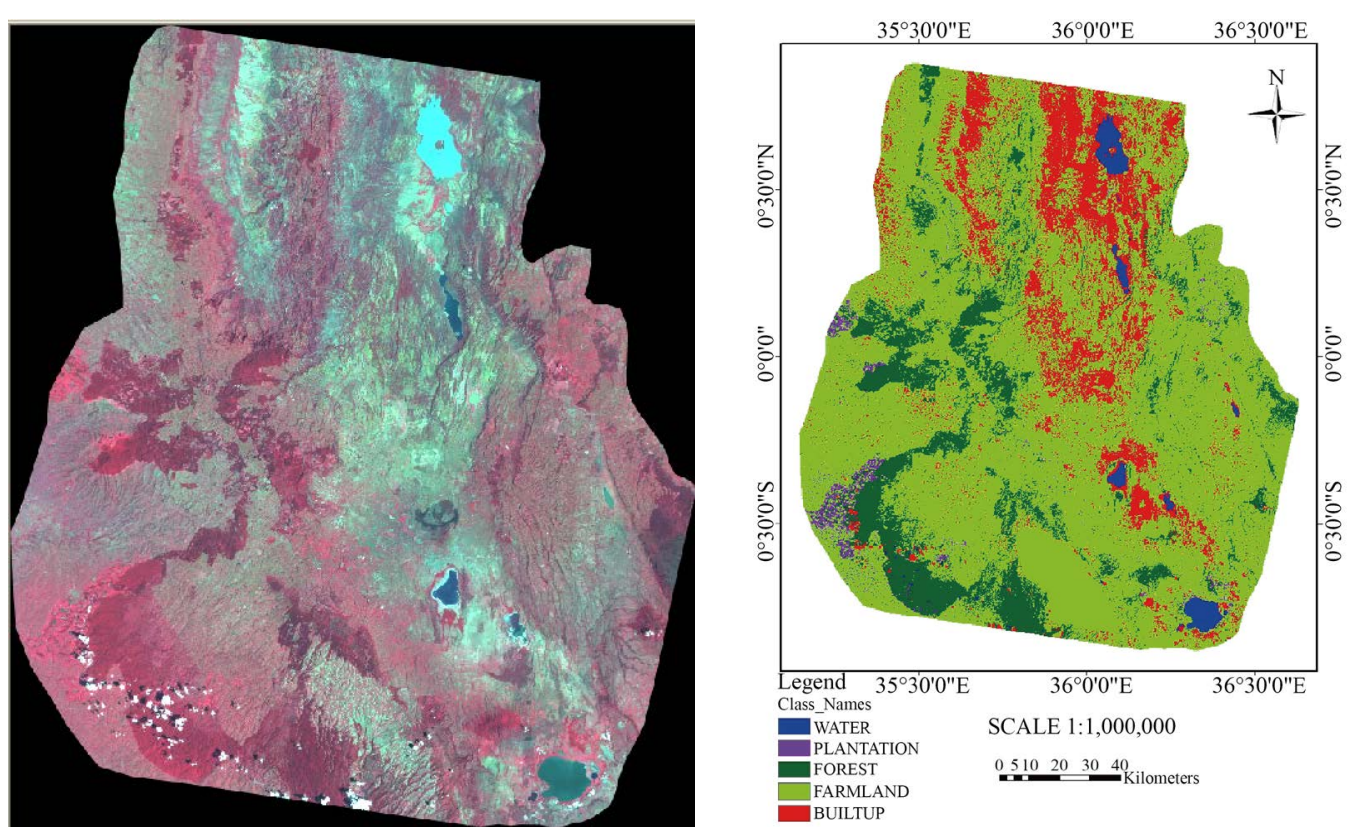

Figure 5. Landsat ETM+2010 image and its classification.

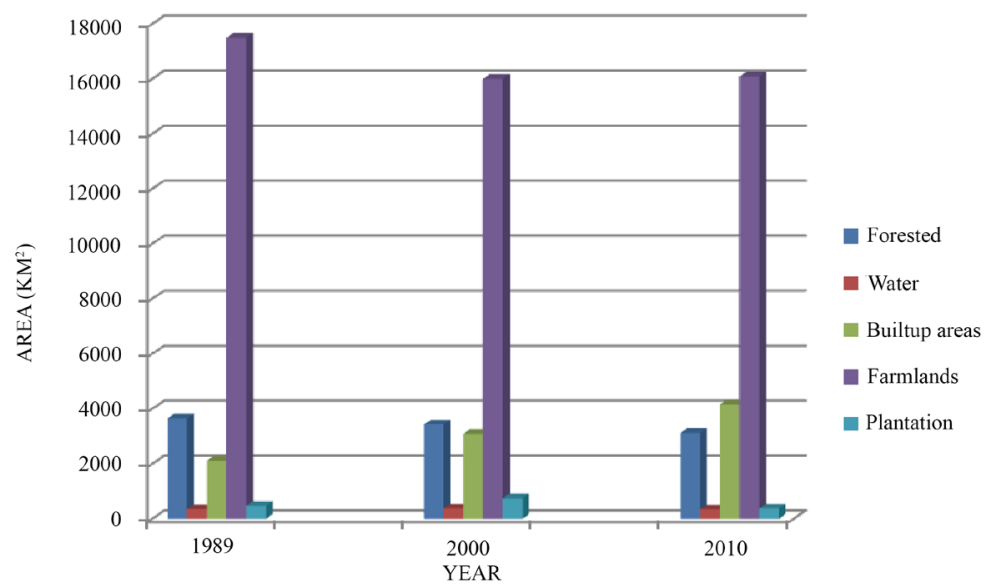

Figure 6. Land use and land cover quantification.

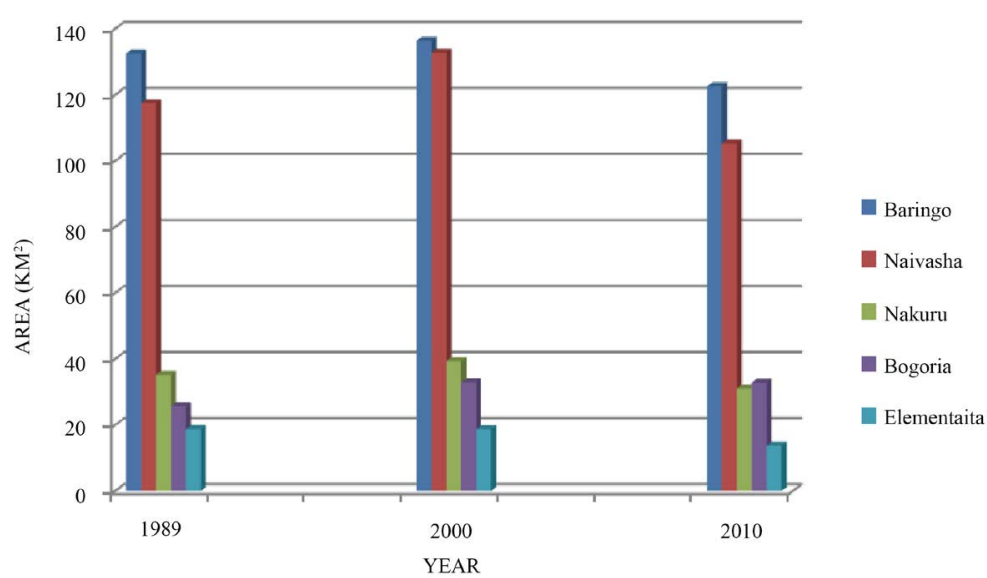

Figure 7. The dynamics of Great Rift Valley lakes in their water surface areas. 


\section{Conclusion and Recommendations}

\subsection{Conclusions}

The study showed that Mau forest cover depletion between 1989 and 2010 registered a percentage decrease of approximately 7\%. These changes are due to human activities for their own economic gains. Increased destruction of forest to transform to farmlands is evident in the Mau through charcoal burning and overgrazing. Population increase in the densely populated areas is a factor to the land use and land cover changes. On the other hand, the dynamics of water bodies have shown that between the year 1989 and 2000, water volumes increased which is a contrary to forest cover that has been decreasing as according to this research. Between the year 2000 and 2010 there is a decrease in water bodies as well as in the forest cover. In general the possible factors which might have caused water to increase slightly between the year 1989 and 2000 while the catchment continuously decreased is the El Nino rains experienced in the year 1997 and 1998. Despite of this anomaly, we conclude that the forest catchment depletion is directly linked to the decrease in the waters of the Great Rift Valley lakes in Kenya.

\subsection{Recommendations}

Forest being a very important natural resource and a catchment area, the Government of Kenya should realign the forest boundaries and fence them in order to keep the population around the forest from encroaching into it. Moreover existing policies should be implemented such as the forest Act 2005 in order to reduce the depletion of the forest. The environmental conservation education should be introduced in schools, colleges and the general public through, "barazas", meetings so that the general public can understand the importance of forest cover as a water catchment area. A fact not to avoid, more research can be performed in order to understand the dynamics of water bodies, there is need to get more information about both underground inlet and outlet of the lakes. This will help in obtaining the real figures of measurements of change since it in this study the inlet flow and outlet flows from the lake were not quantified via remote sensing techniques.

\section{Acknowledgements}

I thank the department of Geomatic Engineering and Geospatial Information Systems for allowing me to work on this research. The support in terms of time, software and literature is highly appreciated.

\section{References}

[1] Dorren, L.K., Maier, B. and Seijmonsbergen, A.C. (2003) Improved Landsat-Based Forest Mapping in Steep Mountainous Terrain Using Object-Based Classification. Forest Ecology and Management, 183, 31-46. http://dx.doi.org/10.1016/S0378-1127(03)00113-0

[2] Fassnacht, K.S., Gower, S.T., MacKenzie, M.D., Nordheim, E.V. and Lillesand, T.M. (1997) Estimating the Leaf Area Index of North Central Wisconsin Forests Using the Landsat Thematic Mapper. Remote Sensing of Environment, 61, 229-245. http://dx.doi.org/10.1016/S0034-4257(97)00005-9

[3] Pellikka, P.K., Lötjönen, M., Siljander, M. and Lens, L. (2009) Airborne Remote Sensing of Spatiotemporal Change (1955-2004) in Indigenous and Exotic Forest Cover in the Taita Hills, Kenya. International Journal of Applied Earth Observation and Geoinformation, 11, 221-232. http://dx.doi.org/10.1016/j.jag.2009.02.002

[4] Beentje, H.J. and Ihlenfeldt, H.D. (1990) The forests of Kenya. Mitteilungenausdem Institutfür Allgemeine Botanik Hamburg, 23, 265-286.

[5] Wass, P. (1995) Kenya’s Indigenous Forests. IUCN, Gland, Switzerland, and Cambridge, UK in collaboration with ODA.

[6] Obare, L. and Wangwe, J.B. (1998) Underlying Causes of Deforestation and Forest Degradation in Kenya. World Forest Movement. http://www.wrm.org.uy/deforestation/Africa/Kenya.html

[7] Bosworth, D., Brown, H., Helms, J.A., McCarthy, L.F. and Jenkins, D.H. (2007) Investing in the Future: Ecological Restoration and the USDA Forest Service/RESPONSE: The Forest Service Must Broaden Its Focus Beyond Restoration/ RESPONSE: Ecological Restoration: A Fitting Goal for America’s National Forests. Journal of Forestry, $105,208$.

[8] Chrisphine, O.M., Maryanne, O.A. and Mark, B.K. (2016) Assessment of Hydrological Impacts of Mau Forest, Kenya. Hydrology: Current Research. http://dx.doi.org/10.4172/2157-7587.1000223

[9] Hesslerová, P. and Pokorný, J. (2010) Effect of Mau Forest Clear Cut on Temperature Distribution and Hydrology of Catchment of Lakes Nakuru and Naivasha: Preliminary Study. In: Water and Nutrient Management in Natural and Constructed Wetlands, Springer, Netherlands, 263-273. http://dx.doi.org/10.1007/978-90-481-9585-5_19 
[10] Mango, L.M., Melesse, A.M., McClain, M.E., Gann, D. and Setegn, S.G. (2011) Land Use and Climate Change Impacts on the Hydrology of the Upper Mara River Basin, Kenya: Results of a Modeling Study to Support Better Resource Management. Hydrology and Earth System Sciences, 15, 2245-2258. http://dx.doi.org/10.5194/hess-15-2245-2011

[11] Raini, J.A. (2009) Impact of Land Use Changes on Water Resources and Biodiversity of Lake Nakuru Catchment Basin, Kenya. African Journal of Ecology, 47, 39-45. http://dx.doi.org/10.1111/j.1365-2028.2008.01048.x

[12] Turner, B.L., Meyer, W.B. and Skole, D.L. (1994) Global Land-Use/Land-Cover Change: Towards an Integrated Study. AMBIO Stockholm, 23, 91-95.http://www.jstor.org/stable/4314168?origin=JSTOR-pdf

[13] Fisher, P.F., Comber, A.J. and Wadsworth, R. (2005) Land Use and Land Cover: Contradiction or Complement. Re-Presenting GIS, 85-98.

[14] Carlson, T.N. and Ripley, D.A. (1997) On the Relation between NDVI, Fractional Vegetation Cover, and Leaf Area Index. Remote sensing of Environment, 62, 241-252. http://dx.doi.org/10.1016/S0034-4257(97)00104-1

[15] Mubea, K. and Menz, G. (2012) Monitoring Land-Use Change in Nakuru (Kenya) Using Multi-Sensor Satellite Data. Advances in Remote Sensing, 1, 74-84. http://dx.doi.org/10.4236/ars.2012.13008

\section{Nomenclature}

FOA (Food and Agricultural Organization), GIS (Geographical Information Systems), GNSS (Global Navigation Satellite System), AOI (Area of Interest) and UNEP (United Nation Environmental Program) 